\title{
Study to Define Frequency in Routine Analytical Controls in the Radiolabelling Process
}

\author{
F. Ria ${ }^{1,2}$, G. Albini' ${ }^{3}$, S. Battista ${ }^{3}$, V. Salvatore ${ }^{3}$, R. Messere ${ }^{3}$, A. Bergantin'1, I. Redaelli', P. Bonfanti' ${ }^{1}$, \\ A. S. Martinotti' ${ }^{1}$ P. Gandolfo ${ }^{3}$, S. Papa ${ }^{4}$
}

${ }^{1}$ Medical Physics Unit, Diagnostic Imaging Department, CDI Centro Diagnostico Italiano, Milan, Italy

${ }^{2}$ Alumnus Progetto Diventero' di Fondazione Bracco, Milan, Italy

${ }^{3}$ Nuclear Medicine Unit, Diagnostic Imaging Department, CDI Centro Diagnostico Italiano, Milan, Italy

${ }^{4}$ Diagnostic Imaging Department Director, CDI Centro Diagnostico Italiano, Milan, Italy

Email: francesco.ria@le.infn.it

How to cite this paper: Ria, F., Albini, G., Battista, S., Salvatore, V., Messere, R., Bergantin, A., Redaelli, I., Bonfanti, P., Martinotti, A.S., Gandolfo, P. and Papa, S. (2017) Study to Define Frequency in Routine Analytical Controls in the Radiolabelling Process. Open Access Library Journal, 4: e3602.

https://doi.org/10.4236/oalib.1103602

Received: April 13, 2017

Accepted: June 26, 2017

Published: June 29, 2017

Copyright $\odot 2017$ by authors and Open Access Library Inc.

This work is licensed under the Creative Commons Attribution International License (CC BY 4.0).

http://creativecommons.org/licenses/by/4.0/

\section{(c) † Open Access}

\begin{abstract}
In the radiolabelling process, the frequency of routine analytical testing must be defined with a risk assessment based on different factors (Pharmeuropa Vol. 26 No. 2, 5.19). Aim of this study is to define the criteria based on the risk assessment required for setting the frequency of analytical controls. 331 preparations of three different radiopharmaceuticals labeled with ${ }^{99 \mathrm{~m}} \mathrm{Tc}$ were examined analyzing temporal trends of radiochemical purity values, potential correlation between radiochemical purity values and total radioactivity content of bulk as well as potential correlation between radiochemical purity values and radioactivity concentration of bulk. The analysis shows no direct correlation between percentage of radiochemical purity and total radioactivity content of preparation and between radiochemical purity values and radioactivity concentration in final bulk solution. Moreover, the routine analytical controls executed for one year on each preparation made it possible to determine how the analytical values do not have inter-operator dependency and there is no evidence of specific temporal trends over time. The study is aimed to assess any eventual criticality related with radiochemical purity tests, determine the possibility of a parametric release and the optimal frequency of tests, without reducing the level of safety of the preparations. This will produce a substantial reduction of costs and of radiation exposure to ionizing radiation of the staff dedicated to Quality Control procedures.
\end{abstract}

\section{Subject Areas}

Radiology \& Medical Imaging 


\section{Keywords}

Analytical Controls, Radiolabelling Process, Frequency, Risk Assessment

\section{Introduction}

In Europe, the preparation and quality control of radiopharmaceuticals from kits is governed by Pharmeuropa Vol. 26 No. 2-5.19 Extemporaneous preparation of radiopharmaceutical preparations [1] and the specific Pharmacopeia Monographies for each product. Furthermore, in Italy, since 2005, this subject has been ruled by a decree issued by the Ministry of Health on 30 March 2005 [2]. Both regulations establish that each preparation must be submitted to a radiochemical purity control before clinical use. However, Annex 17 to the EU Guide to Good Manufacturing Practice [3] sets out that, under specific safety conditions, the parametric release of the product may be undertaken. More specifically, relevant guidance documents, like those published by the PIC/S Committee specify that [4] a reduction in analytical controls on finished products can be considered in the following conditions:

- The demonstration that the test is redundant, i.e. it has not detected any out of alert limit situations, failures or other anomalies not already detected by the remaining system.

- The product quality being assessed is assured, or directly tested by the remaining system.

The goal of this study is to assess any eventual criticality related with radiochemical purity tests, determine the possibility of a parametric release and the optimal frequency of tests on radiopharmaceuticals from kits, while ensuring the same safety standards established by the regulations for such matters and, at the same time, reducing operator exposure to ionizing radiation.

\section{Materials and Methods}

This study examined the work done at the CDI's nuclear medicine radiopharmacy (hot lab) over a 12-month period (September 2013-August 2014), focusing on the preparation of radiopharmaceuticals from kits. During that time, 344 preparations were made, as per the Table 1 . The nuclear medicine radiopharmacy provides radiopharmaceutical solutions for injection for the CDI nuclear medicine department. In the lab there are two hot cells. One cell is dedicated to a FDG dispensing unit. All the radiopharmaceuticals described in this study were made in the second cell that also contains a $99 \mathrm{mTc}$ generator.

All of the preparations were subjected to the analytical controls indicated by the manufacturers in the product characteristics: in particular, the radiochemical purity has been tested with a Thin-layer chromatography technique (silica gel and storage phosphor system). The radiochemical purity tests were performed immediately after radiolabelling processes. All workers perform media fill test twice a year and zero nonconformity were observed. 
Table 1. Number of preparations completed per each radiopharmaceutical between September 2012 and August 2013 in the CDI S.p.A.'s nuclear medicine hot lab.

\begin{tabular}{cc}
\hline Radiopharmaceutical & $\begin{array}{c}\text { Number of } \\
\text { preparations }\end{array}$ \\
\hline DTPA- ${ }^{99 \mathrm{~m}}$ Tc Pentetate Injection (Mallinckrodt SpA, IT) & 63 \\
HDP- ${ }^{99 \mathrm{~m}}$ Tc Oxidronate (Mallinckrodt SpA, IT) & 117 \\
Myoview- ${ }^{99 \mathrm{~m}}$ Tc Tetrofosmin for Injection (GE Healthcare SrL, IT) & 151 \\
Maasol- ${ }^{99 \mathrm{~m}}$ Tc Human Albumin Macroaggregates Injection \\
$\quad$ GE Healthcare SrL, IT) & 7 \\
Ceretec- ${ }^{99 \mathrm{~m}}$ Tc Exametazime Injection (GE Healthcare SrL, IT) & 2 \\
Nanocoll- ${ }^{99 \mathrm{~m}}$ Tc Albumin Colloid (GE Healthcare SrL, IT) & 4 \\
\hline
\end{tabular}

During the preparation processes for the radiopharmaceuticals from kits in nuclear medicine, radiochemical purity can essentially be influenced by three factors:

- Manual skill of workers;

- Radioactivity concentration of the bulk;

- Total radioactivity content in the bulk.

For the purpose of this study the data have been analyzed on a semi-quantitative level. In particular, to demonstrate that the radiochemical purity of radiopharmaceuticals from kits prepared at the nuclear medicine facility is not influenced by the aforementioned three factors this document analyzes the following:

- Trends over time for radiochemical purity values;

- Potential correlation between the values for radiochemical purity and the total radioactivity of the preparation [5];

- Potential correlation between the same radiochemical purity values and radioactivity concentration [5].

This study refers to the DTPA, HDP and Myoview preparations. For the other three types of preparations, given the limited statistics, it is not possible to put forward similar assessments.

\section{Results}

No values outside of the specifications were identified and they were routinely administered to patients. Table 2 show maximum, minimum and median radiochemical purity values for DTPA, HDP, Myoview and Maasol preparations and all radiochemical purity values observed for Ceretec and Nanocoll.

\subsection{Analysis of Trends over Time for Radiochemical Purity Values}

Figures 1-3 show the trends as a function of time for radiochemical purity values, for the period under examination. For the simple moving average, the period for the trendline is equal to 5 . The charts included are for DTPA, HDP and Myoview. For the remaining three kits, the limited number of preparations completed makes any analysis of trends over time impossible. For Maasol, Cere- 
Table 2. Maximum, minimum and median radiochemical purity values for DTPA, HDP, Myoview and Maasol preparations. All values are provided for Ceretec and Nanocoll due to low clinical use of both radiopharmaceuticals in CDI S.p.A.'s nuclear medicine unit.

\begin{tabular}{ccccccc}
\hline & DTPA & HDP & Myoview & Maasol & Ceretec & Nanocoll \\
\hline Min & $95.0 \%$ & $95.0 \%$ & $90.5 \%$ & $95.5 \%$ & & \\
Max & $99.2 \%$ & $99.2 \%$ & $98.8 \%$ & $99.0 \%$ & $96.0 \% ; 97.4 \%$ & $95.6 \% ; 98.2 \% ;$ \\
Median & $96.5 \%$ & $96.2 \%$ & $96.1 \%$ & $98.6 \%$ & & \\
Legal limit & $95.0 \%$ & $95.0 \%$ & $90.0 \%$ & $95.0 \%$ & $95.0 \%$ & $95.0 \%$ \\
\hline
\end{tabular}

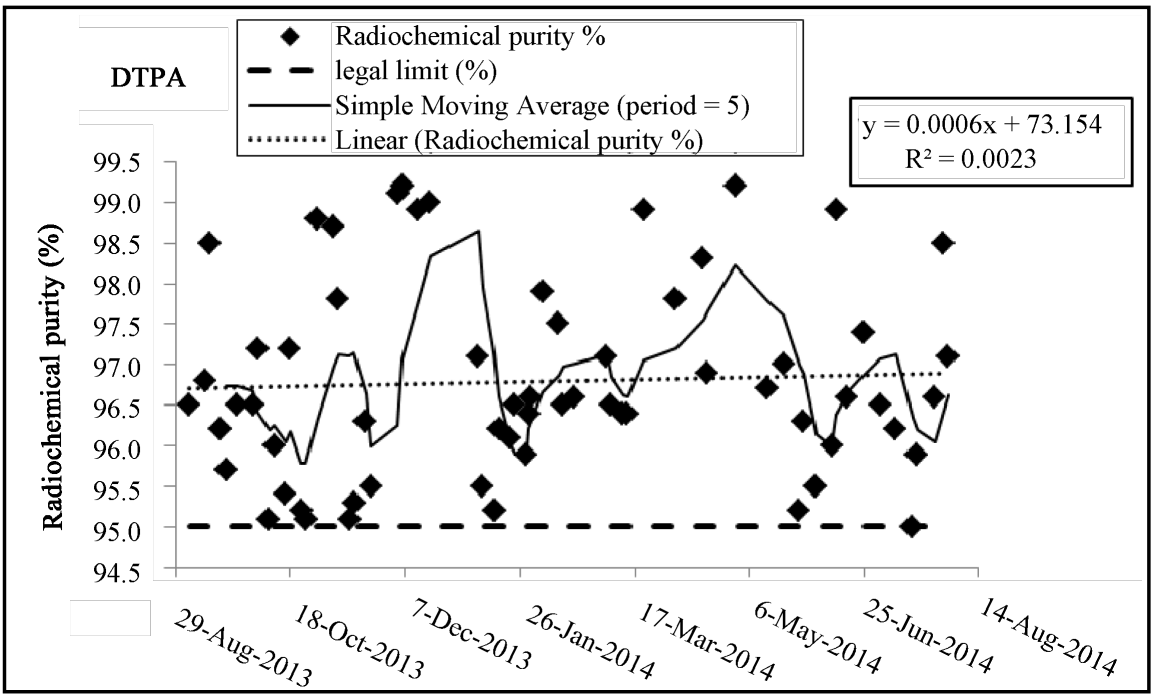

Figure 1. Trend over time for the radiochemical purity of DTPA-Tc99m Pentetate Injection.

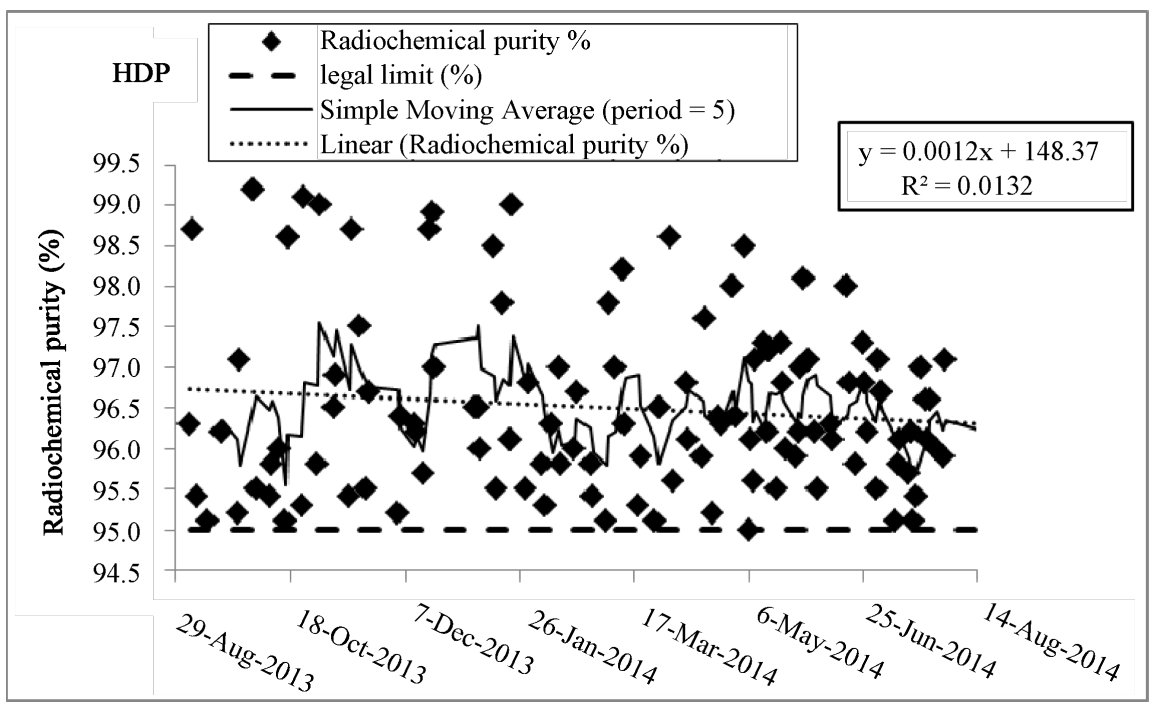

Figure 2. Trend over time for the radiochemical purity of HDP-Tc99m Oxidronate.

tec and Nanocoll, it can be merely noted that no values outside of the quality specifications were found during the analytical controls.

As can be seen from the charts, it is not possible to identify any specific trends 
over time during the observation period.

\subsection{Study of the Correlation between Total Radioactivity and Radiochemical Purity}

The following Figures 4-6 show, for DTPA, HDP and Myoview radiopharmaceuticals, the distribution of radiochemical purity in relation to the total radioactivity content of the bulk.

The charts also contain the linear interpolation parameters and the values of the correlation index (R) squared. (The radioactivity data has been adjusted to the values used in standard clinical practice.).

As shown, there is no correlation between the variation in the radiochemical purity values and the radioactivity content of the bulk. Therefore, it is possible to

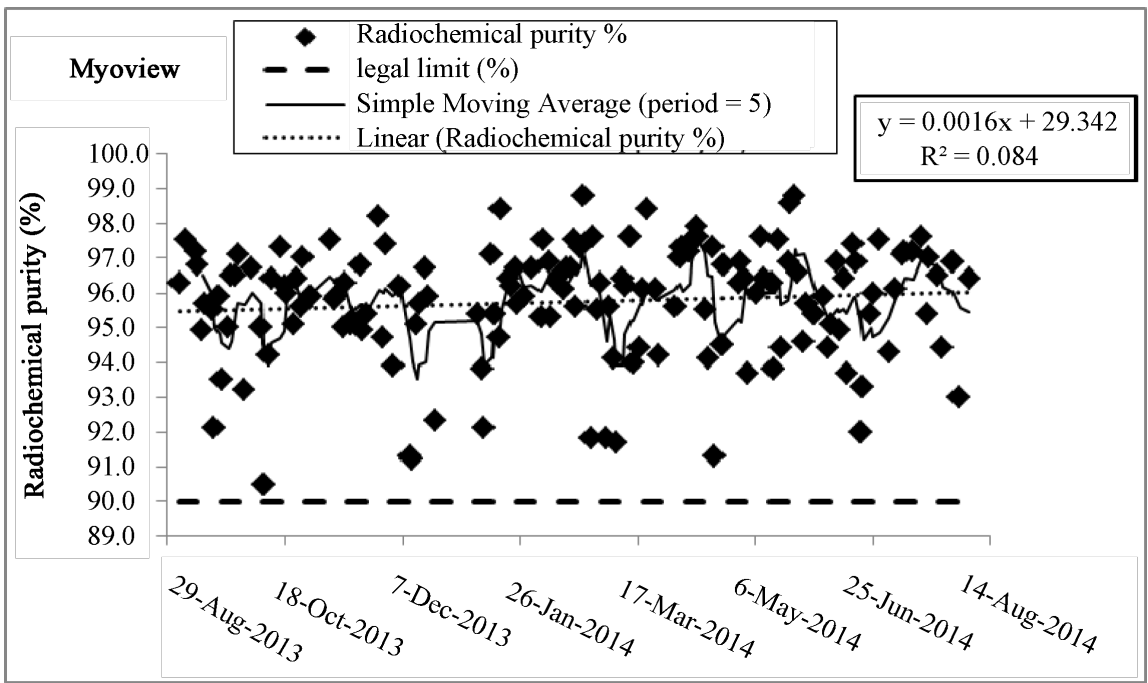

Figure 3. Trend over time for the radiochemical purity of Myoview-Tc99m Tetrofosmin for Injection.

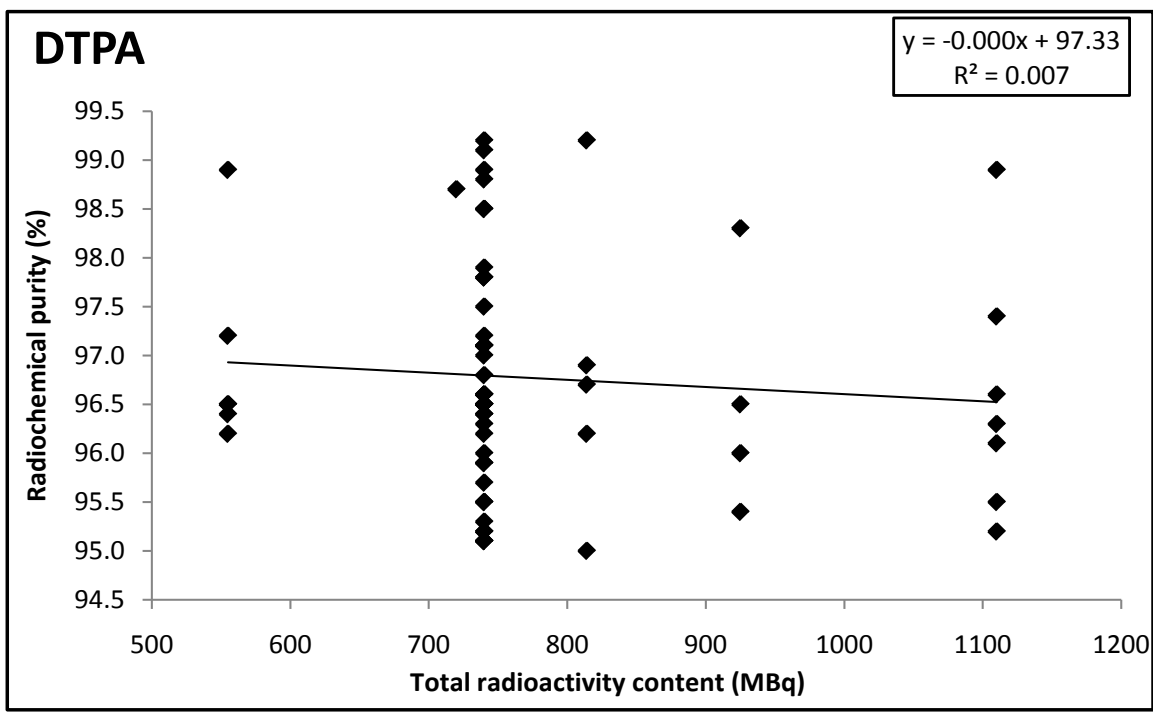

Figure 4. Chart of the correlation between total radioactivity and radiochemical purity of DTPA-Tc99m Pentetate Injection. 


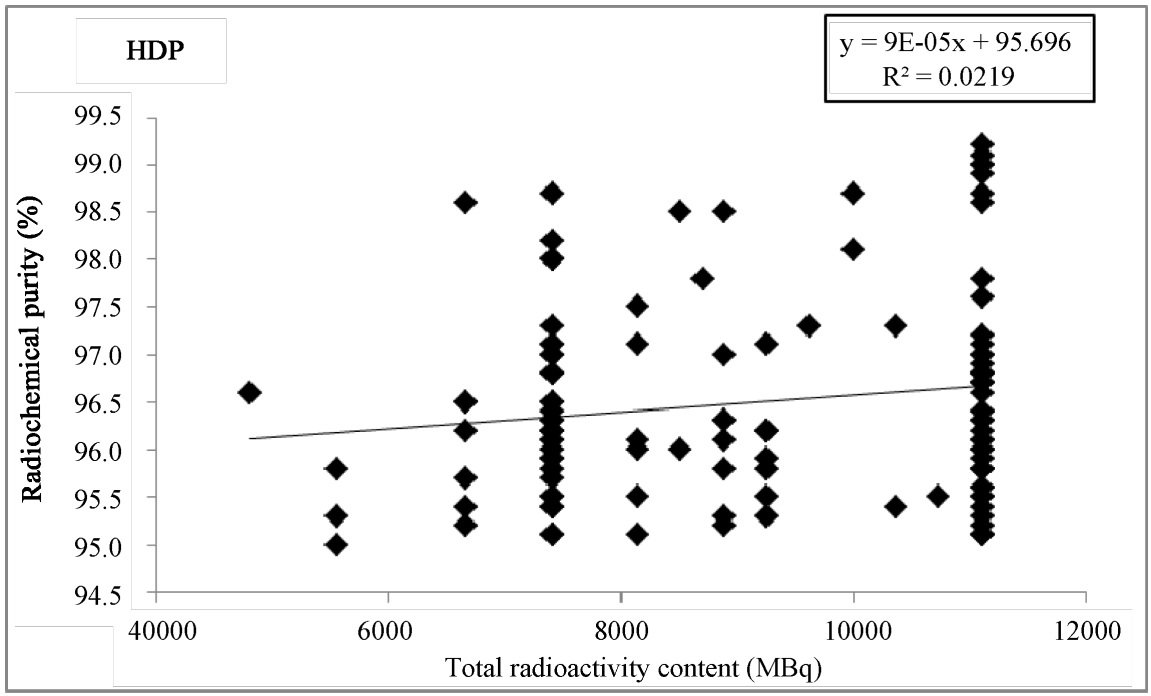

Figure 5. Chart of the correlation between total radioactivity and radiochemical purity of HDP-Tc99m Oxidronate and.

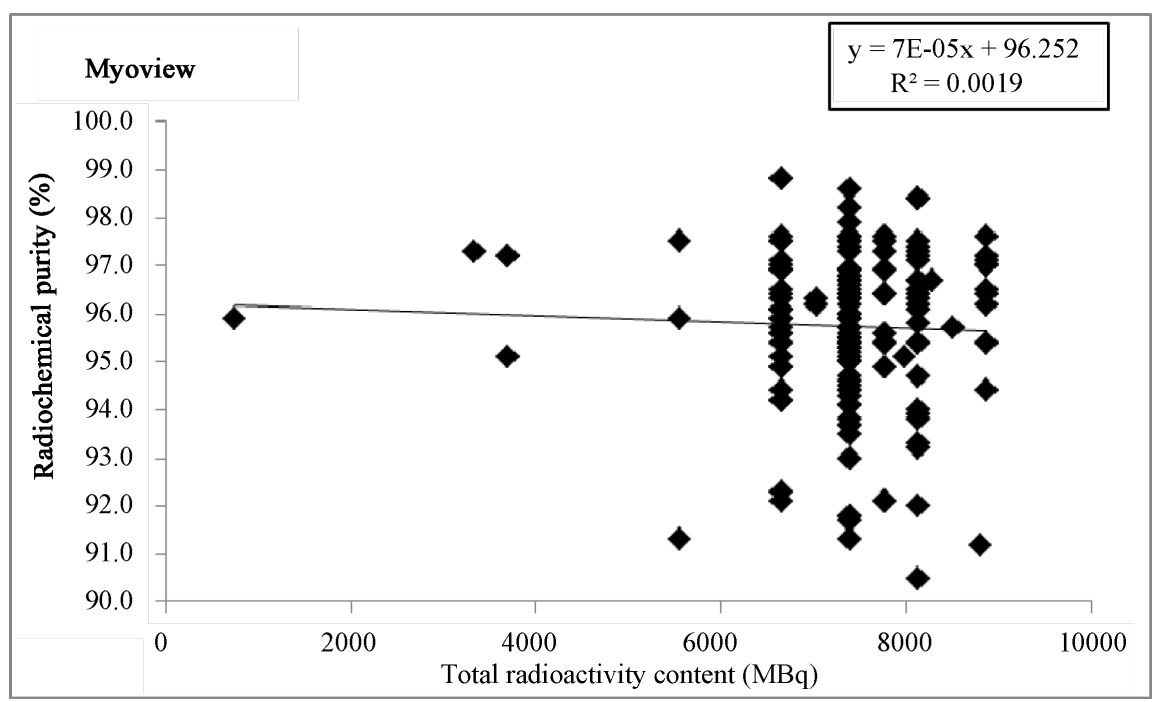

Figure 6. Chart of the correlation between total radioactivity and radiochemical purity of Myoview-Tc99m Tetrofosmin for Injection.

rule out that the percentage of radiochemical purity might decrease with increased radioactivity levels, at least for the radioactivity intervals contained in the preparations created at CDI S.p.A.'s nuclear medicine hot lab.

\subsection{Study of the Correlation between Radioactivity Concentration and Radiochemical Purity}

The following charts show, for DTPA, HDP and Myoview radiopharmaceuticals, the distribution of radiochemical purity in relation the radioactivity concentration $(\mathrm{MBq} / \mathrm{ml})$ of the bulk preparation.

The charts also contain the linear interpolation parameters and the values of the correlation index (R) squared (Figure 7).

As clearly shown by the charts, the values of radiochemical purity do not cor- 
relate with the radioactivity concentration levels of the preparation. Therefore, it is possible to rule out that the percentage of radiochemical purity might decrease with increased radioactivity concentration, at least for the radioactivity intervals contained in the preparations created at CDI S.p.A.'s nuclear medicine hot lab (Figures 7-9). (The radioactivity concentration data has been adjusted to the values used in standard clinical practice.).

\section{Discussion}

The data shows that it is not possible to identify specific trends over time apparently related to manual skill workers.

Furthermore, this parameter is independent of the radioactivity concentration of the final preparation and the total radioactivity levels. The frequency of quality

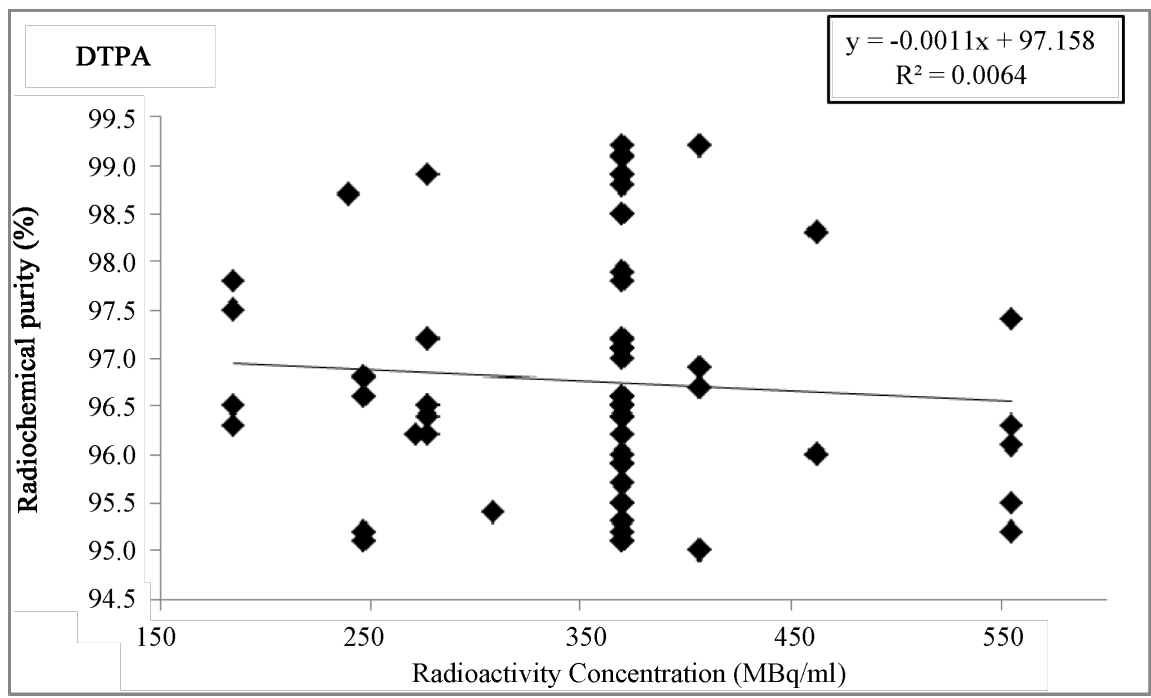

Figure 7. Chart of the correlation between the radioactivity concentration of the solutions and radiochemical purity of DTPA-Tc99m Pentetate Injection.

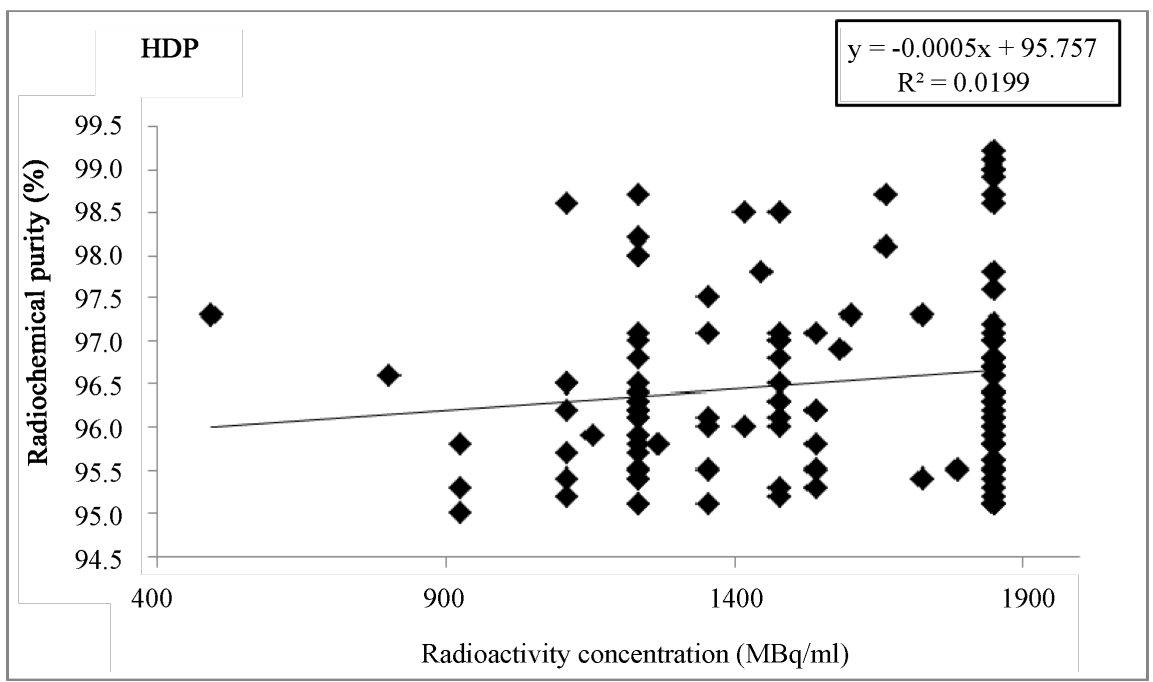

Figure 8. Chart of the correlation between the radioactivity concentration of the solutions and radiochemical purity of HDP-Tc99m Oxidronate. 


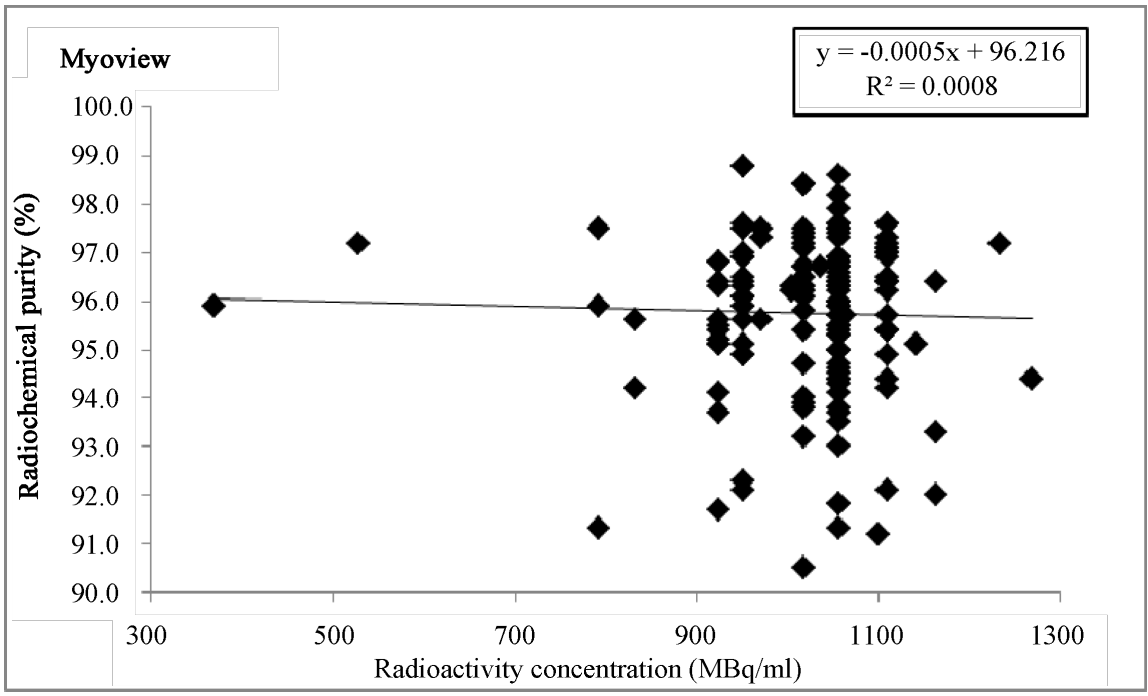

Figure 9. Charts of the correlation between the radioactivity concentration of the solutions and radiochemical purity of Myoview-Tc99m Tetrofosmin for Injection.

controls proposed by the Italian regulatory framework and by Pharmeuropa Vol. 26 No. 2-5.19 Extemporaneous preparation of radiopharmaceutical preparations seems excessive in centers that comply with the highest quality standards. More specifically, such centers are those where the preparations are completed in grade A isolators (Annex 1-EU Guide to Good Manufacturing Practice [6]), based on standard operating procedures, and strictly complying with the preparation instructions provided by the kit supplier, which is authorized to market these products by EU regulatory bodies and which uses marking and fractionating procedures for radiopharmaceuticals that are validated using media fill both initially and at regular intervals.

The data reported herein has been obtained after a year of controls performed regularly on all the preparations.

Given such initial statistical information and the working conditions, it may be considered to apply the concept of parametric release, in compliance with the PIC/S document entitled "Recommendation on Guidance on Parametric Release-Appendix 2" [4].

This would result in considerable savings in the solvents and consumables needed to perform quality controls (estimated at around 78\%) [7].

In addition, reduced control frequency means a reduction in the extremity doses operators are exposed to during quality controls [8] [9].

\section{References}

[1] EDQM (2014) General Chapter 5.19, Extemporaneous preparation of Radiopharmaceutical preparation, Pharmeuropa, 26, 1-10

[2] The Ministry of Health (2005) Approvazione Primo Supplemento alla XI Edizione della Farmacopea Ufficiale della Repubblica Italiana. Repubblica Italiana Decreto del Ministero della Salute 30 marzo 2005, Decree of the Italian Republic.

[3] European Commission (2001) Parametric Release, Annex 17 EudraLex Volume 4 
Good Manufacturing Practice (GMP) Guidelines. European Commission, Brussels.

[4] PIC/S Secretariat (2007) Recommendation of Guidance on Parametric Release. Pharmaceutical Inspection Convention Pharmaceutical Inspection Co-Operation Scheme, PIC/S Secretariat, 25 September 2007.

[5] Walters, L.R., Martins, K.J., et al. (2012) Stability Evaluation of (18) F-FDG at High Radioactive Concentrations. Journal of Nuclear Medicine Technology, 40, 52-56. https://doi.org/10.2967/jnmt.111.097287

[6] European Commission (2008) Manufacture of Sterile Medicinal Products, Annex 1 EudraLex Volume 4 Good Manufacturing Practice (GMP) Guidelines. European Commission, Brussels, Belgium.

[7] Chittò, G., Domenico, E.D., Gandolfo, P., Ria, F., Tafuri, C. and Papa, S. (2013) Risk Assessment and Economic Impact Analysis of the Implementation of New European Legislation on Radiopharmaceuticals in Italy: The Case of the New Monograph Chapter Compounding of Radiopharmaceuticals (PHARMEUROPA, Vol. 23, No. 4, October 2011). Current Radiopharmaceutical, 6.

[8] Delacroix, D., Guerre, J.P., Leblanc, P. and Hickman, C. (2002) Radionuclide and Radiation Protection Data Handbook, 2nd Edition. Radiation Protection Dosimetry, 98, 9-18.

[9] Ginjaume, M., Carinou, E., Vanhavere, F., Gualdrini, G., Clairand, I. and Sans Merce, M. (2010) The ORAMED Project: Optimisation of Radiation Protection for Medical Staff, Europena ALARA Newsletter, Issue 26.

http://www.eu-alara.net/index.php/newsletters-mainmenu-37/52-alara-newsletter-i ssue-26-february-2010/220-oramed.html

Submit or recommend next manuscript to OALib Journal and we will provide best service for you:

- Publication frequency: Monthly

- 9 subject areas of science, technology and medicine

- Fair and rigorous peer-review system

- Fast publication process

- Article promotion in various social networking sites (LinkedIn, Facebook, Twitter, etc.)

- Maximum dissemination of your research work

Submit Your Paper Online: Click Here to Submit

Or Contact service@oalib.com 